\title{
Caminho, Verdade e Vida Unidade entre Teologia, Bíblia e Espiritualidade em S. Boaventura
}

\section{Way, Truth and Life Unity between Theology, Bible and Spirituality according to St. Bonaventure}

\author{
Antonio C. M. Mota
}

\section{Resumo}

A presente comunicação visa mostrar como, através de uma teologia da Palavra de Deus, S. Boaventura elabora uma teologia na qual existe uma profunda unidade entre teologia em geral, Bíblia e Espiritualidade. Essa unidade se dá através da exploração do dogma cristológico, expresso pelo Doctor Seraphicus como Triplex Verbum Patris, ou seja: Verbo eterno, Verbo encarnado e Verbo espirado. Essas modalidades do Verbum correspondem, respectivamente, à Verdade, ao Caminho da Fé, e à Vida em Deus. É justamente a conjugação dessa tríplice modalidade da Palavra que permite ao trabalho teológico a unidade acima referida.

Palavras-chave: Unidade, teologia, Palavra de Deus e espiritualidade.

\section{Abstract}

This presentation is proposed to explain the unity of Theology, Bible and Spirituality which exists in Saint Bonaventura's Theology. This combination results from Doctor Seraphicus' approach to Christological dogma; this is expressed as triplex verbum patris, that is: Eternal Word, Incarnate Word 
and Expired Word. These are the three forms of the Word, which correspond, respectively, to the Truth, the Way of faith and the Life in God. The combination of these three forms is exactly what allows unity which has been discussed already.

Keywords: Unity, Theology, Word of God, Spirituality.

\section{Introdução}

A reflexão em torno da espiritualidade é uma realidade muito nova no contexto da ciência teológica e seu início se deu quando, em 1934, com a Constituição Apostólica Deus scientiarum Dominus, Pio XI instituía as disciplinas Ascética e Mística no currículo das faculdades de teologia católicas, tentando, assim, resolver os problemas do divórcio que há séculos se tinha instalado entre teologia e espiritualidade. Todavia, as novas disciplinas traziam consigo uma série de dificuldades epistemológicas derivantes de um conflito mais originário que era, na verdade, o estranhamento entre teologia e vida; nessa direção, a reflexão em torno da espiritualidade foi-se cada vez mais direcionando para a existência cristã e, a partir daí, as disciplinas Ascética e Mística deram lugar à Teologia Espiritual - da qual faz referência a Constituição Apostólica Sapientia Christiana, de 1979 - que, por sua vez, se delineia cada vez mais como teologia da vida espiritual, revelando, assim, a persistente dificuldade de relação que existe entre espiritualidade e teologia em geral.

Essa dificuldade, como já acenado, consiste no estranhamento entre teologia e vida, como mostra grande parte da produção teológica do século passado que, através de uma pluralidade de tendências ${ }^{1}$, procurou uma maneira de expressar a mensagem cristã em relação e incidência com a vida concreta. Tendências essas que vão desde o historicismo de Harnack ${ }^{2}$, passando pela assim chamada reviravolta antropológica, até as "diversas teologias", com a quais se adentrou o século XXI e nas quais - ou em muitas delas - o "dogma" cristão se encontra obnubilado ou confuso - como se pode constatar, como disse Clodovis Boff ${ }^{3}$, por exemplo, na Teologia da Libertação, para não falar

\footnotetext{
${ }^{1}$ Para uma ampla visão sobre o cenário teológico do século passado, cf. GIBELLINI, R., $A$ teologia do século XX. São Paulo: 1998.

${ }^{2}$ Cf. VON HARNACK, A. Von. L'esssenza del cristianesimo. Brescia: Queriniana, 2003.

${ }^{3}$ Cf. BOFF, C., Teologia da libertação e volta ao fundamento. Revista Eclesiástica Brasileira 268 (2007) 1001-1022.
} 
de sua última expressão, ou seja: a "Teologia Latino-americana Pluralista da Libertação"4 - e, por isso, talvez distante da experiência concreta do "povo de Deus" que, em sua maioria, alimenta sua experiência de fé em nossas paróquias, onde escuta a Palavra de Deus e celebra os sacramentos.

Em muitos casos, viu-se as causas desse estranhamento ente teologia e vida na presença da conceitualidade helenística no dogma cristão e, por isso, tentou-se superar tal estranhamento procurando fundamentar a teologia nas Escrituras; uma tentativa em direção da qual o próprio Concilio Vaticano II se voltou, como se pode ver, sobretudo, através da Dei Verbum; todavia, nessa perspectiva, em muitos casos, predominou - seguramente por influência do método histórico-crítico - uma visão segundo a qual a Palavra de Deus foi resumida à sola Scriptura, o que, além de transformar o cristianismo em uma religião do Livro, colocou como fonte da teologia uma realidade de "ordem documentária, dificultando o trabalho do teólogo dogmático, justamente porque aí impera uma abordagem que se limita àquilo que a tradição chamou sentido histórico-literal das Escrituras ${ }^{5}$ - há pouco tempo atrás não era incomum se escutar mesmo nas homilias dominicais - para a perplexidade dos fiéis - expressão, tais como: "a intenção do autor" ou, em casos mais exagerados, "o sitz in leben do texto". Tamanha foi a dificuldade nesse campo que o Magistério teve que elaborar um texto que tratasse justamente da "Interpretação da Bíblia na Igreja". ${ }^{6}$

Nessa direção, não é raro que se encontre uma produção teológica e exegética limitadas ao âmbito acadêmico, não conseguindo ir ao encontro da sede espiritual presente mesmo no ser humano de hoje, o qual, em geral, procura saciar essa sede em outras fontes que se encontram bem longe daquilo que, geralmente, refletimos na faculdade de teologia, dentro da qual a exegese e teologia da vida espiritual - enquanto disciplinas teológicas - encontram o seu lugar.

\footnotetext{
${ }^{4}$ Sobre esta última tendência teológica, cf. VVAA. Pluralismo e Libertação. Por uma teologia Latino-Americana Pluralista a partir da Fé Cristã. São Paulo: Loyola, 2005. Para um estudo crítico sobre este argumento, cf. GOMES, R. Jesus Cristo na Teologia Pluralista da Libertação Latino-Americana. Uma aproximação sistemática. Miscellanea Francescana 112 (2012) 125-153.

${ }^{5}$ BORDONI, M. Dal Concilio Vaticano II al terzo millennio: il travaglio di um teólogo. In: ID. Christus omnium Redemptor. Saggi di Cristologia. Città del Vaticano: Libreria Editrice Vaticana, 2010, p. 29-31.

${ }^{6}$ PONTIFÍCIA COMISSÃO BÍBLICA. A interpretação da Bíblia na Igreja. São Paulo: Paulinas, 1994.
} 
No cenário da teologia do século passado, H. U. Von Balthasar foi um dos teólogos que mais se deteve sobre essa problemática ${ }^{7}$ e descreve-a dizendo que teologia e espiritualidade - que deveriam formar um só corpo - encontram-se uma - a teologia entendida como dogmática - como um esqueleto sem carne e a outra - a espiritualidade - como carne sem osso. Todavia, aquilo que é mais pertinente na obra do Teólogo suíço consiste na constatação segundo a qual esse estranhamento não é originário na teologia; a teologia cristã nasce em profunda sintonia com a espiritualidade, uma sintonia que se dava justamente com a mediação das Escrituras.

Nessa perspectiva, em seu conhecido ensaio "Teologia e Santidade", Von Balthasar coloca S. Boaventura entre os últimos teólogos em cujas teologias se pode verificar uma profunda unidade entre dogmática, Bíblia e espiritualidade.

Explorando essa constatação balthasariana, pretende-se, nas paginas que se seguem, mostrar como, através de uma teologia da "Palavra de Deus", o Doctor Seraphicus, mantem a unidade acima referida que é, justamente, a unidade originária da teologia cristã.

\section{Palavra e teologia em Boaventura}

Naturalmente, cada coisa tende ao seu lugar de origem: a pedra cai, a chama sobe e os rios escorrem em direção ao mar [...]. A criatura racional é deiforme, e pode retornar ao seu lugar de origem através da memória, da inteligência e da vontade, e não é pia se não re-funda si mesma sobre o seu lugar de origem (BOAVENTURA, Collationes de septem donis Spiritus Sancti, 3,5-6).

Segundo a teologia boaventuriana, a finalidade da vida humana é voltar para sua origem que é Deus, de quem, através da palavra que lhe foi dada, o ser humano é imagem; e, assim, sendo a palavra o lugar onde a diferença entre o humano e o divino encontra seu ponto de unidade, é através da palavra que o homem encontra sua via de retorno ao lugar de onde se deu inicio o seu próprio ser. Isto significa que o caminho humano de retorno à sua origem é um caminho que passa pelo conhecimento que se dá através da palavra.

\footnotetext{
${ }^{7}$ Sobre o que acima foi colocado, Bathasar se detem, sobretudo, naquilo que se pode considerar o "esboço" de sua teologia, ou seja: uma serie de artigos reunidos na obra que recebeu o título de Verbum caro, cf. H. U. VON BALTHASAR. Verbum caro. Skizzen zur Theologie 1. Freiburg: Johannes Verlag Einsiedeln, 1960 (para esta comunicação nos servimos da tradução italiana: Verbum caro. Saggi di teologia 1. Milano-Brescia: Jaca Book-Morcelliana, 2005.
} 
Também na perspectiva boaventurina, a palavra, que se expressa no "dizer", tem a função de comunicar, implicando, portanto, uma relação dialógica entre pessoas e, nesse sentido, tem um lugar privilegiado no coração da própria vida divina que, enquanto vida trinitária, acontece através de um "diá-logo" tripersonal que forma a comunhão de amor, que é a identidade do Deus cristão ${ }^{8}$.

A vida trinitária, como sabemos, em ato de liberdade e transbordamento de amor, se comunica para além de si mesma, em ato criador, cujas obras "são" justamente expressão dessa comunicação e, assim, concreções do Dei Verbum. Destarte, a propria criação, para o Teólogo franciscano, já é teologia, justamente porque já é um discurso de Deus, feito através do Verbum increatum, por meio do qual todas as coisas foram feitas. Para Boaventura, a criação é um livro, a livro da Natura, escrito por Deus para que a partir dela o ser humano O encontrasse, por isso cada ser natural é um vestigio que fala de Deus, ou melhor, por ele, Deus criador fala de si mesmo ${ }^{9}$. Na perspectiva boaventuriana, Essa é a primeira teologia, ou seja, uma teologia descendente ${ }^{10}$; esse discurso que Deus faz de si mesmo, com a finalidade de dar-se a conhecer, culmina na revelação do Verbum incarnatum, através do qual, pela fé, pôde-se ver o rosto de Deus, como lemos na Carta aos Hebreus:

Muitas vezes e de modos diversos falou Deus, outrora, aos Pais pelos profetas; agora, nestes dias que são os últimos, falou-nos por meio do Filho, a quem constituiu herdeiro de todas as coisas e pelo qual fez o mundo. ${ }^{11}$

Ainda na perspectiva da teologia do Doctor Seraphicus, existe a teologia que é o discurso que nós fazemos com Deus e, na mesma linha, o discurso que elevamos a Deus, por isso uma teologia ascendente:

como oração, feito no Espirito Santo, mediante o Filho re-percorrendo, ao inverso, a teologia divina, mediante um processo ordenado que Boaventura chama recondução. Mediante a invocação de um desejo ardente, "o homem

${ }^{8}$ Cf. MAIO, A Di. Piccolo glossário bonaventuriano. Introduzione al pensiero e al lessico di Bonaventura da Bagnoregio. Roma: Aracne, 2008, p. 23.

${ }^{9}$ DOCTORIS SERAPHICI S. BONAVENTURAE. Itinerarium mentis in Deum, I,2. In: ID. Opera theologica selecta, vol. V. Firenze: Quaracchi, 1964 (todas as citações das obras de S. Boaventura feitas na presente comunicação são do original latino, traduzidas pelo autor da mesma comunicação).

${ }^{10}$ MAIO, A. Di. O.c., p. 23.

${ }^{11} \mathrm{Hb} 1,1-3$. 
de grande desejo" está em grau (como o profeta Daniel) de receber as grandes revelações de Deus na maneira adequada: "essa é exatamente a religião cristã, que consiste na piedade". ${ }^{12}$

Portanto, a nossa teologia é, em primeiro lugar, expressão de nossa experiência de Deus que se nos revela. Essa experiência da comunicação de Deus, que gera um diálogo com Deus, pode dar lugar a uma Palavra; uma "Palavra-Mémoria" da experiência que lhe dá origem, a qual, quando escrita por inspiração, se torna Palavra de Deus em palavras humanas, Palavra de fé. Trata-se da Palavra das Sagradas Escrituras, como confirma, biblicamente, Boaventura, quando fala a respeito do conhecimento que vem através da fé:

Não por vontade humana foi feita jamais uma profecia, mas, inspirados pelo Espírito Santo, aqueles homens falaram da parte de Deus $(2 \mathrm{Pd} 1,21) .{ }^{13}$

Assim, na perspectiva boaventuriana, existem dois livros através dos quais podemos chegar a Deus: O livro da Natura, e o Livro das Escrituras. Todavia, como as Sagradas Escrituras são fruto de inspiração, existe também o Livro do coração, lugar onde Deus fala através de seu Verbum, antes que este se torne Palavra escrita. Esclarece Boaventura:

O conhecimento da fé [...] se dá em dois modos, ou seja: com a revelação e com a autoridade. De fato, diz Agostinho no livro De utilitate credende: "aquilo que compreendemos, devemo-lo à razão, aquilo que cremos, devemo-lo à autoridade. Mas não existiria autoridade se não existisse antes a revelação [...]. A partir do momento em que somente por estas duas vias é possível chegar ao conhecimento que se realiza pela fé, isto não acontece senão por um dom de Cristo, princípio de toda revelação, em virtude da vinda na mente, e fundamento de toda autoridade, em virtude da sua vinda na carne. ${ }^{14}$

Assim, o Doctor Seraphicus, segundo o qual a teologia não visa outra coisa senão levar o ser humano à contemplação, diz que existe um triplo modo de chegar a Deus através da teologia (triplex intellectus):

\footnotetext{
${ }^{12}$ MAIO, A. Di. O. c., p. 24.

${ }^{13}$ SANCTI BONAVENTURAE. Christus unus omnium Magister, 5. In: ID. Sermones Theologici/2. Roma: Città Nuova, 1995.

${ }^{14}$ Ibidem, 2.
} 
A chave da contemplação é um tríplice conhecimento, ou seja: o conhecimento que se dá através do Verbo eterno, mediante o qual todas as coisas são feitas; o conhecimento que se dá através do Verbo encarnado, pelo qual todas as coisas são reparadas; e o conhecimento que se dá através do Verbo espirado pelo qual todas as coisas são reveladas. ${ }^{15}$

\section{O Triplex Verbum}

Deus se pronuncia, portanto, através de um tríplice modo de falar que, na teologia bonaventuriana, é chamado Triplex Verbum, o qual quer dizer que o Verbum Patris ecoa no tempo, de acordo com a pedagogia divina, como Verbum Increatum, Verbum Incarnatum e Verbum Inspiratum.

\subsection{O Verbum Increatum}

O conhecimento que se obtem através do Verbum increatum é o conhecimento que se refere à verdade de todas as coisas, já que estas foram feitas através do Verbo eterno de Deus.

A vida trinitária, como sabemos, em ato de liberdade e transbordamento de amor, se comunica para além de si mesma, em ato criador, cujas obras "são", justamente, expressão dessa comunicação e, assim, concreções do Dei Verbum.

É, portanto, o conhecimento pela leitura do Livro da Natura. Para o Teólogo franciscano toda a obra da criação - cujos seres são uns vestigios outros imagens de Deus - é como que uma escada pela qual se pode ascender a Deus. Para isto ao ser humano - que é imagem - foi dado um tríplice olhar sobre o mundo que lhe permite essa ascensão mediante o conhecimento, ou seja: o olhar do corpo, o olhar da alma, o olhar do espírito. Em estado original, o ser humano, com este tríplice olhar, pode conhecer as coisas que estão fora de si, as coisas que então dentro de si, e, enfim, as coisas que estão acima de si, onde contempla Deus ${ }^{16}$.

Todavia, por causa do pecado, o terceiro olhar perdeu sua luz, o segundo ficou ofuscado, restando à condição humana, como conhecimento seguro,

${ }^{15}$ SANCTI BONAVENTURAE. Collationes in Hexaëmeron. Siue illuminationes Ecclesiae, III, 2. In: ID. Sermones Theologici/1. Roma: Città Nuova, 1994 (para as próximas citações será usada a seguinte abreviação: Hex., seguida do respectivo capítulo e parágrafo).

${ }^{16}$ DOCTORIS SERAPHICI S. BONAVENTURAE. Itinerarium mentis in Deum, I,2. 
somente o conhecimento do corpo que se expressa como conhecimento racional da realidade.

Uma vez que o segundo olhar não se tornou completamente cego, pela filosofia que, na concepção boaventuriana, consiste na leitura e meditação do livro da natureza em vista de uma contemplação sapiencial de Deus, constitui o nível mas elevado do pensamento humano, mas, uma vez que a inteligência filosófica, perscrutando o mundo, de modo obscuro, pode intuir que deve existir um Verbo eterno ordenador do cosmo, mas não pode chegar a afirmar que tal Verbo seja a Segunda Pessoa da Santíssima Trindade, para a contemplação de Deus, permanece um conhecimento manco ${ }^{17}$.

\subsection{O Verbum incarnatum}

Para libertar o ser humano de um conhecimento estanque, por assim dizer, "dentro dos limites da própria razão", impedido, portando, de conhecer e amar o que está acima de si; Deus, que faz tudo através de sua Palavra, revelou-se como Verbum incarnatum, o qual funda e garante o conhecimento que dá através da fé e recapitula, recria, todas as coisas. No sermão In nativitate Domini, escreve o Teólogo franciscano:

Assim como o Pai criou todas as coisas mediante o Verbo Incriado; da mesma forma, recriou todas as coisas, como diz Agostinho, através do Verbo Encarnado. ${ }^{18}$

O Verbum incarnatum é a Pessoa de Jesus Cristo que como Verbum abbreviatum, encerra em si toda a Escritura. Nas "conferências" In Hexaëmeron, diz Boaventura:

A chave do conhecimento da fé [...] é o conhecimento do Verbo encarnado, mediante o qual todas as coisas são reparadas. No Evangelho de Lucas, no último capítulo, se lê: "são estas as palavras que vos dizia quando ainda estava convosco: era preciso que se cumprissem as coisas escritas ao meu respeito na lei de Moisés, nos Profetas e nos Salmos. Então, abriu a mente deles para que compreendessem as Escrituras." 19

\footnotetext{
${ }^{17}$ Cf. MAIO, A Di., O. c., p. 37.

${ }^{18}$ Tradução, feita pelo Autor do presente estudo, da seguinte passagem: "Sicut enim Pater per Verbum increatum omnia fecit, ita per Verbum incarnatum, ut dicit Augustinus, omnia refecit" (Sancti Bonaventurae, Commentarius in Evangelium Lucae, VI,17, in: ID., Opera omnia, vol. VII, Firenze: Ed. Quaracchi, 1895, p. 139).

${ }^{19}$ Hex., III, 10.
} 
Toda a Escritura fala, portanto, do Verbum incarnatum que - mesmo sendo a Pessoa de Jesus Cristo, que, na plenitude dos tempos, se revela, no seio da Virgem Maria, como encarnação do Verbum increatum que no principio criou todas as coisas - depois da paixão, morte e Ressurreição, é encontrado nos dois Testamentos, que, juntos, revelam o Cristo total:

Símbolo disso [diz o Doctor Seraphicus] são os dois Querubins que, com as faces voltadas para o propriciatório, estavam voltados um em direção ao outro. Os dois Querubins são os dois Testamentos, os quais se referem a Cristo. ${ }^{20}$

Portanto, na história que se dá depois do Tríduo Pasqual, o Verbum incarnatum é contido na Bíblia, que lida unitariamente, funda o conhecimento de Cristo como o Verbum Patris que funda o conhecimento da fé.

Todavia, assim como o Jesus pré-pascal era uma pessoa composta por duas naturezas - uma humana, outra divina - o Corpo escriturístico - isto é, a Bíblia - possui também duas dimensões, uma literal e outra espiritual ${ }^{21}$. Por isso, com a finalidade de chegar à contemplação de Deus, mesmo a partir da Bíblia, não basta uma leitura da littera; para colher o spiritus da Escritura, e desse modo contemplar Deus, faz-se necessário lê-la no Espírito de Cristo que é dom.

Deste modo, para falar da compreensão das Escrituras na história que se dá depois do Tríduo Pascal, Boaventura - conforme foi citado acima - usa passagem lucana dos Discípulos de Emaús (cf. Lc 24, 44-45), onde é justamente o Cristo Ressuscitado que, vindo ao encontro dos discípulos, lhes dá a compreensão das Escrituras.

\subsection{O Verbum inspiratum}

O episódio do encontro do Ressuscitado com os Discípulos de Emaús, mostra que é Cristo vivo no Espírito, vindo ao encontro da comunidade, quem revela ao fiel o completo conhecimento do Verbum incarnatum como conhecimento da segunda Pessoa da Trindade, ou seja: permite reconhecer Jesus Cristo como o Filho de Deus Salvador.

\footnotetext{
${ }^{20}$ Ibidem, III, 11.

${ }^{21}$ Para uma compreensão mais ampla sobre a maneira de ler a Bíblia em Boaventura, cf. LUBAC, H. De. Esegesi medievale. I quattro sensi della Scrittura, vol. 4. Milão: Paoline-Jaca Book, 2006, p. 325-336.
} 
Portanto, aí se revela uma terceira modalidade do Verbum Patris. Para nomear tal modalidade do "dizer do Pai", o Doctor Seraphicus, na maturidade do seu pensamento, tomando uma expressão que se encontra solta em Bernardo de Claraval, insere na sua teologia o "conceito teológico" Verbum inspiratum, que fala dessa vinda de Cristo na mente do fiel, proporcionando-lhe o "sabor" das escrituras, o seu conhecimento espiritual. ${ }^{22}$

\section{Teologia ministerial: teologia como ministério eclesial}

A revelação do Verbum Patris como Triplex Verbum, ou seja: Verbo eterno, Verbo encarnado e Verbo espirado, concente que se tenha um conhecimento de Deus que abarque integralmente o fiel, pois aí se conjugam intelecção - pela presença do Verbo eterno que impulsiona a pessoa a procurar a verdade das coisas -, fé - caminho de vida apontado pela Sagrada Escritura - e piedade - presença de Cristo no coração do fiel, que lhe dá o sentido espiritual da Palavra.

Além de tudo, essa revelação de Deus, que se dá através do Triplex Verbum, se mostra como revelação radicalmente cristológica, pois o Verbo é justamente o Filho de Deus: que se encontra, desde sempre, no seio do Pai; que, na plenitude dos tempos, se encarnou no seio da Virgem Maria e que agora, no Espírito, é presente, no seio da Igreja, por sua presença no coração dos fiéis como Verbo espirado. Por isso, Ele próprio diz no Evangelho de São João: Eu sou o Caminho, a Verdade e a Vida. Segundo Boaventura: enquanto Caminho, é o Verbo encarnado, em cujos passos encontramos a via que leva a Deus; enquanto Verdade é o Verbo eterno, pelo qual encontramos a verdade de todas as coisas; enquanto Vida é o Verbo espirado no qual, pela contemplação de Deus, temos a vida. ${ }^{23}$

Essa teologia da Palavra, na perspectiva boaventuriano subsiste na vida dos homens santos, os quais ornam a vida da Igreja, sendo eles mesmos lugares teológicos onde se pode ver essa revelação integral do Verbo que é Cristo. Os Santos - para o Teólogo franciscano, sobretudo São Francisco - são homens nos quais, pela profunda intimidade com Cristo, que se dá pela contemplação, todas as coisas aparecem em sua limpidez originária, as Escrituras aparecem como fonte de frutos espirituais, e tudo isto pela presença espiritual de Cristo, como Verbo espirado, em seus corações. ${ }^{24}$

${ }^{22}$ Cf. Hex., III, 22.

${ }^{23}$ Cf. Hex., III, 32.

${ }^{24} \mathrm{Cf}$. Ibidem, IX,8. 
A Igreja, em cuja vida se constata a presença do Verbo de Deus, tem a função de fazer Cristo crescer no coração dos próprios fiéis, o que dá lugar à teologia como ministério eclesial: a teologia dos teólogos, que são homens de fé a serviço da missão da Igreja ${ }^{25}$.

A teologia ministerial se configura, portanto, como ciência da fé. Enquanto ciência, é feita através do conhecimento racional, mas o seu ponto de partida continua sendo a fé e seu escopo é justamente estreitar a relação do fiel com Deus, uma relação que se inicia com a fé - cuja porta é o Verbo encarnado - e culmina na contemplação amorosa - operada pelo verbo espirado. ${ }^{26}$

Desta forma, a teologia dos teólogos, porque científica, tem um método muito preciso, mostra-o Boaventura:

[Porque] o Verbo que é Cristo é Caminho, Verdade e Vida, como é dito no capítulo quarto de João, existe uma tríplice gradualidade de conhecimento certo e justo, como escreve Ugo no De Sacramentis: "Estes são os três graus de crescimento da fé, com os quais a fé, aumentando, chega à perfeição: primeiro: escolher por devoção; segundo: aprovar através da razão; terceiro: aprender por meio da verdade [...] O primeiro se realiza através de uma adesão fiel ao consenso religioso; o segundo se realiza com a certeza que deriva do raciocínio seguro; o terceiro se obtém através do esplendor da pura contemplação [...]. Existem, portanto, três formas diversas de conhecimento: da fé, dedutiva, contemplativa, e, de todas estas, Cristo é o princípio e a causa: a primeira enquanto caminho, da segunda enquanto verdade, da terceira enquanto vida. ${ }^{27}$

Enquanto Caminho, Cristo é o Verbo encarnado, presente na Bíblia, ponto de partida da teologia ministerial; enquanto Verdade, Cristo é o Verbo eterno, pelo qual se indaga em sintonia com a Escritura; enquanto vida, Cristo é o Verbo espirado, que revelando progressivamente o sentido da Escritura, leva o fiel à contemplação do mistério escondido nas Páginas bíblicas.

A teologia aparece, portanto, como conhecimento que se obtém a partir da Bíblia, em função do crescimento espiritual do cristão. E desta maneira, a teologia, enquanto ministério eclesial, é revelada em profunda unidade com a Bíblia e, porque sua finalidade é levar à contemplação, só pode se configurar como teologia espiritual:

${ }^{25}$ Cf. Ibidem, I, 1-5.

${ }^{26}$ Cf. Christus unus omnium Magister, 15.

${ }^{27}$ Christus unus omnium Magister, 1. 
O método que permite chegar à sabedoria consiste em começar pela certeza da fé, continuar pela clareza da razão, para chegar à doçura da contemplação. Isto nos fez entender Cristo quando disse: Eu sou o caminho, a verdade e a vida [...] Este é o método que os Santos usaram, prestando atenção a quanto disse Isaías, segundo uma outra versão: Se não acreditais, não compreendereis. ${ }^{28}$

Depois, além do método, existe o autor da Teologia que é, em última instância, Cristo que, discurso integral de Deus ${ }^{29}$, é o único Mestre, como se diz no Evangelho de Mateus; destarte, a comunhão com Cristo é conditio sine qua non para o exercício do ministério teológico. Ele - diz o Teólogo franciscano - é primeiro Mestre de teologia, de modo que pelos segundos - aqueles que exercem o ministério teológico na Igreja:

[...] deve ser, antes de tudo, honrado, escutado e interrogado. [...] Deve ser honrado não somente com palavras ou discursos, mas realmente, pela imitação. [...] Deve ser escutado com humildade da fé, como está escrito no capítulo cinquenta de Isaías: o Senhor me deu uma língua de discípulo para que eu pudesse trazer ao cansado uma palavra de conforto: em cada manhã faz atento, faz atento o meu ouvido para que eи o escute como a um mestre. [...] Deve ser interrogado pelo desejo de aprender, e não pela curiosidade ou incredulidade, que interrogam para pôr à prova. ${ }^{30}$

\section{À guisa de conclusão}

O estudo de um teólogo do passado é relevante para a teologia do presente, não na medida em que nos oferecem doutrinas, mas porque nele encontramos uma atitude teológica capaz de dar um horizonte em tempo de desorientação, de desafios.

Nesse sentido, a reflexão boaventuriana sobre a Palavra de Deus lança luzes sobre os desafios oriundos das tensões existentes entre teologia, Bíblia e espiritualidade, na medida em que nos recorda que estas são instâncias que giram em torno da vida de fé e, conseqüentemente, somente aí encontram a sua unidade e, até mesmo, sua razão de ser.

\footnotetext{
${ }^{28}$ Christus unus omnium Magister, 15.

${ }^{29}$ Cf. Ibidem, 16.

${ }^{30}$ Cf. Ibidem, 20-22.
} 
De acordo com essa perspectiva, o teólogo é, por natureza, um homem de fé, mas de uma fé que seja cristã; portanto, segundo a Tradição, composta pelo próprio ato de crer (fides qua) e um conteúdo que lhe precede (fides quae). É esse conteúdo - por exigência da própria pessoa que crê - que precisa ser interrogado, compreendido, desvelado, pela atividade teológica; é por isso que Boaventura, seguindo a Tradição, diz que o método teológico consiste em fazer uma "pergunta de fé".

Um pergunta de fé só pode nascer de uma relação, de um diálogo com Deus que se nos apresenta em seu Verbo Encarnado, ou seja, nas Escrituras Sagradas. Destarte, para Boaventura, o teólogo é o fiel que honra, escuta e interroga a Cristo. Nessa direção, sua teologia é "dia-logo" com o seu Senhor, é mística, é caminho espiritual através da Palavra, é expressão de espiritualidade bíblica. Por isso ele - chamado Doctor Seraphicus - é reconhecido pela Igreja, concomitantemente, como teólogo, pastor e santo.

\section{Referências Bibliográficas}

BALTHASAR, Hans Urs Von. Verbum caro. Saggi di teologia/1. MilanoBrescia: Jaca Book-Morcelliana, 2005.

BORDONI, M. Dal Concilio Vaticano II al terzo millennio: il travaglio di um teólogo. In: ID. Christus omnium Redemptor. Saggi di Cristologia. Città del Vaticano: Libreria Editrice Vaticana, 2010, p. 13-42.

BOFF, Clodovis. Teologia da libertação e volta ao fundamento. Revista Eclesiástica Brasileira 268 (2007) 1001-1022.

DOCTORIS SERAPHICI S. BONAVENTURAE, Itinerarium mentis in Deum. In: ID. Opera theologica selecta, vol. V. Firenze: Quaracchi, 1964.

GIBELLINI, Rosino. A teologia do século XX. São Paulo: Loyola, 1998.

GOMES, R., Jesus Cristo na Teologia Pluralista da Libertação LatinoAmericana. Uma aproximação sistemática. Miscellanea Francescana 112 (2012) 125-153.

HARNACK, Adolf Von. L'esssenza del cristianesimo. Brescia: Queriniana, 2003.

LUBAC, Henri De. Esegesi medievale. I quattro sensi della Scrittura, vol. 4. Milão: Paoline-Jaca Book, 2006. 
MAIO, A Di. Piccolo glossário bonaventuriano. Introduzione al pensiero e al lessico di Bonaventura da Bagnoregio. Roma: Aracne, 2008.

PONTIFÍCIA COMISSÃO BÍBLICA. A interpretação da Bíblia na Igreja. São Paulo: Paulinas, 1994.

SANCTI BONAVENTURAE. Commentarius in Evangelium Lucae, VI,17, in: ID., Opera omnia, vol. VII, Firenze: Ed. Quaracchi, 1895.

Collationes in Hexaëmeron. Siue illuminationes Ecclesiae. In: ID., Sermones Theologici/1. Roma: Città Nuova, 1994.

. Christus unus omnium Magister. In: ID. Sermones Theologici/2. Roma: Città Nuova, 1995.

VVAA. Pluralismo e Libertação. Por uma teologia Latino-Americana Pluralista a partir da Fé Cristã. São Paulo: Loyola, 2005.

Antonio C. M. Mota

Mestre em teologia espiritual pela PUA (Roma) Docente no Centro Franciscano de Espiritualidade (Piracicaba-SP)

Piracicaba/SP - Brasil

E-mail: theologia.amoris@gmail.com

Recebido em: 01/06/13

Aprovado em: 07/03/14 
